\title{
Threats Shift Immigrants' Attention from Their Home Country to Host Society: Evidence from the September 11 Terrorist Attacks
}

\author{
Jae Yeon Kim ${ }^{*}$ Andrew Thompson ${ }^{*}$
}

June 17, 2021

\begin{abstract}
This study uses a natural experiment and machine learning to examine how threats shift immigrants' political attention from their home country to host society. We trace how the September 11 attacks, an exogenous shock, increased Arab and Indian Americans' interest in U.S. domestic politics. We classified 5,684 Arab American and Indian American newspaper articles using machine learning. We estimated that three more articles on U.S. domestic politics were published daily in the post-9/11 period than in previous years. We found that the intervention produced a $46 \%$ smaller effect among the host population by analyzing 23,086 New York Times articles. The findings demonstrate how threats shift the locus of targeted immigrant groups' political attention.
\end{abstract}

\footnotetext{
*Corresponding author. PhD Candidate, Department of Political Science, University of California, Berkeley, 210 Barrows Hall 1950, Berkeley, CA 94720, USA jaeyeonkim@berkeley.edu

†Postdoctoral Fellow, Department of Political Science, University of Notre Dame, 2060 Jenkins Nanovic Halls, Notre Dame, IN 46556, USA athomp24@nd. edu

${ }^{\ddagger}$ All replication code is available at https://github.com/jaeyk/ITS-Text-Classification.

$\S$ The project received administrative support from the UC Berkeley Data Science Discovery program. We thank Chris Bail, David Harding, Heather A. Haveman, Yan Shuo Tan, Isaac Dalke, Hero Ashman, and participants at the joint Political Computational Science and Political Network 2020 conference and the inaugural meeting of the Berkeley Computational Social Science Forum for their constructive comments. Carlos Ortiz, Sarah Santiago, and Vivek Datta provided excellent research assistance.
} 
Historical examples have shown that threats, exclusionary state policies and native hostility, increased the targeted immigrant groups' interests in their host society's politics and urged them to organize politically. For instance, in nearly a direct response to the Chinese Exclusion Act, a federation of Chinese family and clan associations, the Chinese Consolidated Benevolent Association (CCBA), was founded in 1882 in San Francisco to protect Chinese immigrants' interests (Lai, 2004, Ngai, 2014). The Japanese American Citizens League, the Japanese equivalent of the CCBA, was formed in 1929, five years after the Immigration Act of 1924 established the Asiatic Barred Zone that banned Japanese entering the U.S. (Hosokawa, 1982, Fugita and OBrien, 2011).

Immigrants live between the two worlds; their home country and their host county. This duality is especially pronounced among rapidly growing immigrant populations. First-generation immigrants are usually more interested in the politics of their home country than host society. This occurs because they have close social ties to their home country, and learning a new political environment is costly due to language and cultural barriers. Scholars have documented how this tendency creates tension between the first- and second-generation immigrants (Wong, 1977, Espiritu, 1992, Wei, 1993, Umemoto, 1989, Võ, 2004, Umbach and Wishnoff, 2008, Ishizuka, 2016, Kim, 2020, Bleakley and Chin, 2008, Foner and Dreby, 2011). It also explains how children help their parents' political learning in immigrant families (Cho, 1999, Stepick and Stepick, 2002, Wong, 2000, Carlos, 2021) because they are more acculturated with the host society than their parents.

Threats, the forces that challenge a group's social position, change this dynamic by increasing the cost of political ignorance (Outten et al., 2012, Weeks, 2015). When threats are imminent, ignoring the signals would make the targeted immigrants suffer from the host state's exclusive policies and native hostility. For this existential reason, threats induce targeted immigrant communities to seek more political information, especially related to the treatment of their members in the host society. Shifting political attention is not a matter of choice but survival.

Despite this theoretical and political importance, it is challenging to find large-scale observational evidence on how threats shift immigrant communities' political interest from their home countries to host society because longitudinal surveys on these immigrant communities are rare. We provide 
a solution to this long-standing problem by combining machine learning and a natural experiment. We leverage an exogenous shock that caused a prevalent sense of threat to assess the event's effects on immigrant communities' political learning. We conduct a natural experiment using text data through this shock, specifically analyzing how Arab and Indian Americans engage in politics in the wake of the September 11 terrorist attacks. Through automated classification of 5,684 Arab American and Indian American newspapers, we find that the September 11 terrorist attacks caused both groups to become significantly more interested in U.S. domestic politics. These newspapers published three times more articles on U.S. political news related to Muslim communities per day in the post-9/11 period than in the years leading up to the attacks.

As a point of comparison, we also analyze 23,086 articles of a mainstream publication, the New York Times, and find that the same exogenous shock produced a $46 \%$ smaller effect than the ethnic newspapers. The targeted immigrant groups have expressed far greater interest in Muslims' treatment in the U.S. than the general American public since the September 11 attacks. The findings demonstrate how threats force targeted immigrant groups to pay attention to their host society's politics. In the process, we also developed two open-source software, accompanying $\mathrm{R}$ packages, which help researchers to collect large-scale longitudinal data from mainstream and ethnic newspapers published in the U.S and compare the patterns appearing in them.

\section{Threats, Political Attention, and Immigrant Groups}

Conflict is central to politics. By extension, the concept of threat, the feelings that emerge out of conflict, is a natural outgrowth of this dynamic. Threat has long been considered a central concept within political science, and social sciences generally. The central focus of most work on threat has been about how they influence majority group members' attitudes (Key Jr, 1949, Blumer, 1958, Blalock, 1967, Donald, 1985, Liska, 1992, Quillian, 1996, Wang, 2012, Enos, 2016, Acharya, Blackwell and Sen, 2018). In this tradition, threat emerges out of a perceived loss of status, changing group size, and proximity to minority groups, to say a few. When majority groups 
feel a sense of threat, their prejudicial attitudes toward minority groups increase.

However, racial minority groups in the U.S. are also susceptible to threats. They are subordinate groups in the racial hierarchy and often scapegoated by the government and mainstream media in the wake of national crises (Perea, 1997, Valentino et al., 2019). Despite this, knowledge of how threats affect these marginalized populations is scant. Existing opinion data, such as the American National Election Studies or the General Social Survey, contain only small fractions of observations of minority populations (Outten et al., 2012, Craig, Rucker and Richeson, 2018, Mutz, 2018). The few studies addressing this subject have been limited in their temporal scope (Pantoja and Segura, 2003, Pérez, 2015, Bloemraad, Silva and Voss, 2016, Azab and Santoro, 2017, Zepeda-Millán, 2017, Towler and Parker, 2018, Reny, Wilcox-Archuleta and Nichols, 2018, Gutierrez et al., 2019). Consequently, the investigations of the long-term effects of threats on marginalized populations using observational data have been rare (Cho, Gimpel and Wu, 2006, White, 2016, Zepeda-Millán, 2017).

Among many racial minority groups in the U.S., we focus on immigrant populations. They are particularly vulnerable to threats, emerged by national crises, because of their subordinate racial position and precarious legal status. In the absence of threats, these groups, especially their first-generation members, do not exhibit interest in the politics of the host society as the learning cost is high and the extent to which they can change its direction is limited. Ignoring politics does not help but does not hurt them either.

Threats change these dynamics. Specifically, the negative changes in the political environment, such as exclusive state policies and native hospitality, substantially increase the cost of political ignorance. Facing these challenges, these groups may shift their attention from the politics of their home countries to that of the host society.

The prevailing narrative about knowledge of U.S. politics is that Americans understand little about it, and the situation is worse among marginalized populations (Converse, 1975, Verba, Schlozman and Brady, 1995, Carpini and Keeter, 1996). For example, the poor lack education and resources and have fewer tools to seek more information about the political world. 
Recent studies (Cohen and Luttig, 2019, Weaver, Prowse and Piston, 2019), however, show that this portrayal misses the dual structure of political knowledge among marginalized populations. Political knowledge concerns organized information on how one's government works. On the one hand, marginalized people know little about how the government works responsively because their needs have historically been unmet. On the other hand, they are well informed about how the government oppresses them because that information is crucial for their daily survival and resilience. For instance, black residents of heavily policed neighborhoods have detailed knowledge and understanding of policing (Weaver, Prowse and Piston, 2019). Immigrant communities might know little about how U.S. Congress works. Still, they might be eager to learn aspects of U.S. politics that directly influence their welfare and safety.

Knowing how groups change in light of senses of threat deepens our understanding of how political shocks shape politics. In the wake of the September 11 attacks, Arabs and South Asians became subject to U.S. state surveillance and negative media reporting due to their associations with Muslims (Chandrasekhar, 2003, Cainkar and Maira, 2005, Yazdiha, 2014). We expect that these perceived threats caused them to shift their political attention from their home countries to host society.

\section{Research Design}

We leveraged the September 11 attacks as a natural experiment. We use the terrorist attacks as an intervention because they are an unexpected event. Had the September 11 attacks not occurred, the world would have continued in how it had existed before. This counterfactual world helps identify the intervention's causal effects, as trends in the pre-intervention period can be compared with those in the post-intervention period. This research design is called an interrupted time series design (Campbell and Ross, 1968, Cook and Campbell, 1979). From a theoretical perspective, the September 11 attacks are also relevant because they are also associated with the rise of hawkish policy (i.e., the War on Terrorism) and the xenophobic/Islamophobic public sentiment 
(Panagopoulos, 2006, Lajevardi, 2020). Muslim/Arab/South Asian Americans were subjected to extensive security measures, selective law enforcement and were framed and targeted as potential terrorists in mainstream media (Norris, Kern and Just, 2004, Cainkar and Maira, 2005, Alsultany, 2012, Selod, 2015).

We focus on Arab and Indian Americans, a subgroup of South Asians for multiple reasons. First, they were targeted by U.S. government surveillance, hate crimes, and racial profiling (Chandrasekhar, 2003, Merskin, 2004, Ewing, 2008, Alsultany, 2012). Immediately following the attacks, Arab, Indian, and Muslim Americans, along with other groups that "looked Muslim" experienced heavy amounts of profiling, surveillance and violence (Rudrappa, 2004, Ahluwalia and Pellettiere, 2010, Finn, 2011). In this project, we expect that Arab and Indian Americans will be behaviorally affected in the post-9/11 period in light of this increased targeting by the general public and the American government.

To the broader study of minority political behavior, these small immigrant communities present a significant empirical challenge. A natural experiment that leverages a discontinuity in time requires many observations before and after the intervention. Without a sizable amount of observations, researchers lack the statistical power to reject the null hypothesis. Social scientists usually track behavior changes through surveys. However, many observations of the target populations in this study_Arab and Indian Americans-were unlikely to be captured by most political opinion survey data collected at the national level using probability sampling. For example, in the American National Election Survey, Asians as a racial group constitute 1 percent, 5 percent, and 4 percent in 1998, 2000, and 2002, respectively. This is a dearth in observations, and it also fails to account for heterogeneity among this group and does not capture Arab American identity. We argue that text data from newspapers are a more effective data source, providing more significantly more observations and capturing real-world political behavior.

The Ethnic NewsWatch database, created by ProQuest, contains more than 2.5 million articles published by ethnic media in the U.S. over the last four decades. ${ }^{1}$ We downloaded 5,684 Arab and

\footnotetext{
${ }^{1}$ For more information, see https://about.proquest.com/products-services/ethnicnewswatch_hist.html
} 
Indian American newspaper articles mentioning "Muslims" and randomly sampled 1,015 articles from them ( $18 \%$ of the total data) stratifying on publication sources and intervention periods. The two authors and three undergraduate research assistants coded these sample data as either "domestic" or "international." Then we trained a lasso (Tibshirani, 1996), random forest (Breiman, 2001), and XGBoost (Freund and Schapire, 1999, Friedman et al., 2000) algorithms and selected the best performing model based on its accuracy (the percentage of results accurately classified) and F-score (the weighted average of precision and recall). The number of articles classified as either of the two categories was considered a proxy for measuring the change in different kinds of information seeking (i.e., the shift in political attention from international to domestic politics). This is a reasonable assumption, as newspapers rely heavily on their consumers' demands (McManus, 1994, Cohen, 2002). They are motivated by viewership, which is the attention that people give to the publication. As such, newspapers will adjust to the attention of their consumers by increasing or decreasing their reporting on topics based on the demand. Substantive increases and decreases over time to specific matters therefor indicate publications adjusting to the demands of their viewers.

We estimate the causal effect of the intervention using the model specified in 1. Typically, a segmented regression model is used to estimate these parameters. $Y$ is the dependent variable at time $t$ or the count of published articles per day. Date is the date variable. Intervention indicates the September 11 attacks and is coded " 0 " when the date variable is earlier than September 11, 2011 and " 1 " when the date variable is equal to or later than that date. Group indicates that the data source is either an Arab American or an Indian American newspaper. We focused on estimating $\beta_{1}$, representing the dependent variable's level change between the pre- and post-intervention periods.

$$
Y_{t}=\beta_{0}+\beta_{1} \text { Intervention }+\beta_{2} \text { Date }_{t}+\beta_{3} \text { Group }+\varepsilon
$$

We also examine how the effect of the September 11 attacks on different kinds of information seeking varies between targeted immigrant groups and the general public. To this end, we collected the New York Times articles on Muslims in the U.S. published in the same period. 


\section{Data}

We used a 5-year window before and after the data collection intervention, from September 1996 to September 2006. The decade-long time frame is chosen to show the durability of the causal effect of the intervention. Between June and July 2019, we manually downloaded Arab American and Indian American newspaper articles related to Muslim populations published during this period from the Ethnic News Watch database (for more information, see Table A.1 in Appendix A). We avoided automatically scraping the articles because we did not want to violate ProQuest's Terms of Service. We then saved these articles in Hypertext Markup Language (HTML) format to utilize the metadata (e.g., publication dates).

The ethnic newspaper data included two Arab American (The Arab American News and The Arab American View) and three Indian American (News India Times, India Abroad, and India West) newspapers. The Arab American News is the oldest and most widely circulating Arab American newspaper in the U.S and its content is bilingual. ${ }^{2}$ News Indian Times is a national weekly newspaper published by Parikh Worldwide Media LLC, the largest Indian-American publishing group in the U.S. ${ }^{3}$ The Arab American View is a Chicago-based community newspaper. ${ }^{4}$ Indian Abroad is the oldest Indian newspaper in the U.S. and focused on the Indian diaspora and expatriate readership. ${ }^{5}$ India West is the most circulating Indian newspaper on the West Coast. ${ }^{6}$ Of the 5,684 collected articles, 4,552 were Indian American, and 1,132 were Arab American. ${ }^{7}$ We extracted features from these HTML files and turned them into a data frame in the next step. In this case, the key features were the texts and publication dates. The texts are important to train machine learning algorithms and make predictions. The publication dates are critical for creating the time series data based on these texts. We also created an accompanying $\mathrm{R}$ package, which helps researchers easily utilize the

\footnotetext{
${ }^{2}$ For more information, see https://www.arabamericannews.com/

${ }^{3}$ For more information, see https://www.newsindiatimes.com/about-us/

${ }^{4}$ For more information, see https://www.loc.gov/item/2006225095/

${ }^{5}$ The newspaper ceased to operate in March, 2020. For more information, see https://www.indiawest.com/news/glo bal_indian/indian-american-newspaper-india-abroad-ends-print-edition-after-50-years/article_4927860c-71fe-11eaacf2-9b06758a5865.html

${ }^{6}$ For more information, see http://echo-media.com/medias/details/11575/india+west

${ }^{7}$ For copyright reasons, we cannot share the proprietary text data that we collected for this study.
} 
Ethnic NewsWatch database with little knowledge about the HTML data structure.

To estimate the increase in the coverage of Muslims related domestic and internal news in the mainstream media, we collected the New York Times articles related to Muslims were collected using the New York Time Application Protocol Interface (API) in April 2021. ${ }^{8}$ To ease the research replication process, we created another accompanying $\mathrm{R}$ package, which helps collect long-term time-series data from New York Times search API easily and quickly. Because the New York Times API also provided metadata, we took advantage of it instead of applying machine learning to classify New York Times articles. Specifically, the API offered access to articles and how the newspaper internally classified the articles in different sections and subsections. Leveraging this information, we removed irrelevant articles, such as those on fashion and sports, from the data. ${ }^{9}$ This wrangling process reduced the data's size from 23,086 to 19,797 articles (17\% reduction). The API also offered information on which articles are related to international news. Based on this information, we divided the relevant articles into the domestic and international news.

\section{Hypotheses}

Threats will increase the demand for news reports on targeted group members which motivates our following expectations. First, the terrorist attacks on 9/11 will increase the political attention of targeted minority groups, which then will lead to an uptick in reporting on Muslims. Media rely on attention from their audience. As a result of this dynamic, we expect that Arab Americans and Indian Americans will be motivated by threat to pay more attention to information about Muslims, thereby causing their group-oriented media to report more on Muslims. Formally our hypothesis is:

- H1: The September 11 attacks made Arab American and Indian American newspapers publish more articles on U.S. political news related to Muslim communities in the post-9/11 period than in previous years.

\footnotetext{
${ }^{8}$ For more information, see https://developer.nytimes.com/

${ }^{9}$ Here is the full list of sections we used to identify these irrelevant articles: "Business Day", "Books", "Arts", "Magazine", "Movies", "Theater", "Sports", "Your Money", "Science", "Technology", "Food", "Health", "Real Estate", "Job Market", "Great Homes Destinations", "Fashion Style", "Style", "Home Garden", "Automobiles", and "Travel."
} 
Second, we expect that threat from the attacks will shift political attention of immigrant communities away from their home countries to their host country. Specifically, this expectation is:

- H2: Arab American and Indian American newspapers published more articles on Muslim populations in the U.S. than outside the U.S. in the post-9/11 period than in the pre-9/11 period.

Third, as a point of comparison, we expect that the general public's political attention toward Muslims will be less affected by the September 11 attacks than targeted immigrant communities. Thus, the media, which represents larger segments of the American public, will publish fewer articles about Muslims when compared to ethnic newspapers. Our formal hypothesis for this expectation is:

- H3: The effect size of the treatment effect would be smaller among the host population than among the targeted immigrant groups.

\section{Results}

\subsection{Automated Text Classification}

We sampled 1,015 articles from this dataset to train machine learning algorithms. We tried to obtain (1) equal-sized sample articles for the pre- and post-intervention periods (intervention variable) and (2) balanced samples from different kinds of newspapers (source variable). The two coauthors and three undergraduate research assistants labeled these 1,015 sample articles ${ }^{10}$ as binary variables depending ${ }^{11}$ on whether they were about U.S. domestic politics (coded "1") or not (coded " 0 ").

\footnotetext{
${ }^{10}$ Ideally, we would have calculated inter-coder reliability by assigning the same articles to at least two coders, but this was not possible due to time restrictions. We hired the undergraduate research assistants through the UC Berkeley Data Science Discovery Program, which requires tangible results within a semester. We acknowledge this a limitation of our study.

${ }^{11}$ Initially, we labeled these articles to indicate whether they were about U.S. domestic politics or not. As we started reading and labeling the sample articles, we realized that most of the non-domestic Muslim articles were about international affairs, such as the disputes between India and Pakistan.
} 
Then we trained a lasso (Tibshirani, 1996), random forest (Breiman, 2001), and XGBoost (Freund and Schapire, 1999, Friedman et al., 2000) algorithms using the labeled texts with the added features (i.e., intervention, source, and group variables). We did this using 'tidymodels' package in R (Kuhn and Wickham, 2020). As for preprocessing, we removed stopwords, normalized the document length using term frequency-inverse document frequency, and restricted the number of features to 1,000 . We also tuned key hyperparameters of each algorithm. The random forest algorithm performed the best in terms of accuracy and F-score. Its accuracy rate was 78\%, and F-score was 76\% (see Figure B.1 in Appendix B).

\subsection{Interrupted Time Series Design Analysis}

We created the time series data needed for the interrupted time series design analysis by combining the classified texts and their publication dates. In Figure 1, the X-axis indicates the publication date, and the Y-axis shows the number of published articles. In panel A, the Y-values show the number of articles on U.S. domestic politics. In panel B, the Y-values show the number of articles on international politics. The dots indicate the raw data, and the line plots indicate the fitted values of the OLS models specified in Model 1. The grey areas represent the 95\% confidence intervals.

The result showed that the increase in articles on U.S. domestic politics was substantial and statistically significant. As shown in Table 1, Arab American and Indian American newspapers published three more articles on U.S. political news related to Muslim communities per day in the post-9/11 period than in previous years. Although the effect size is more than three times smaller, it seems that the treatment effect on articles related to international politics is also statistically significant $(\mathrm{p}<0.01)$. These findings are robust even when we used Eicker-Huber-White robust standard errors (Eicker, 1967, Huber et al., 1967, White, 2014) to account for heteroskedasticity (see Figure C.1 in Appendix C). 


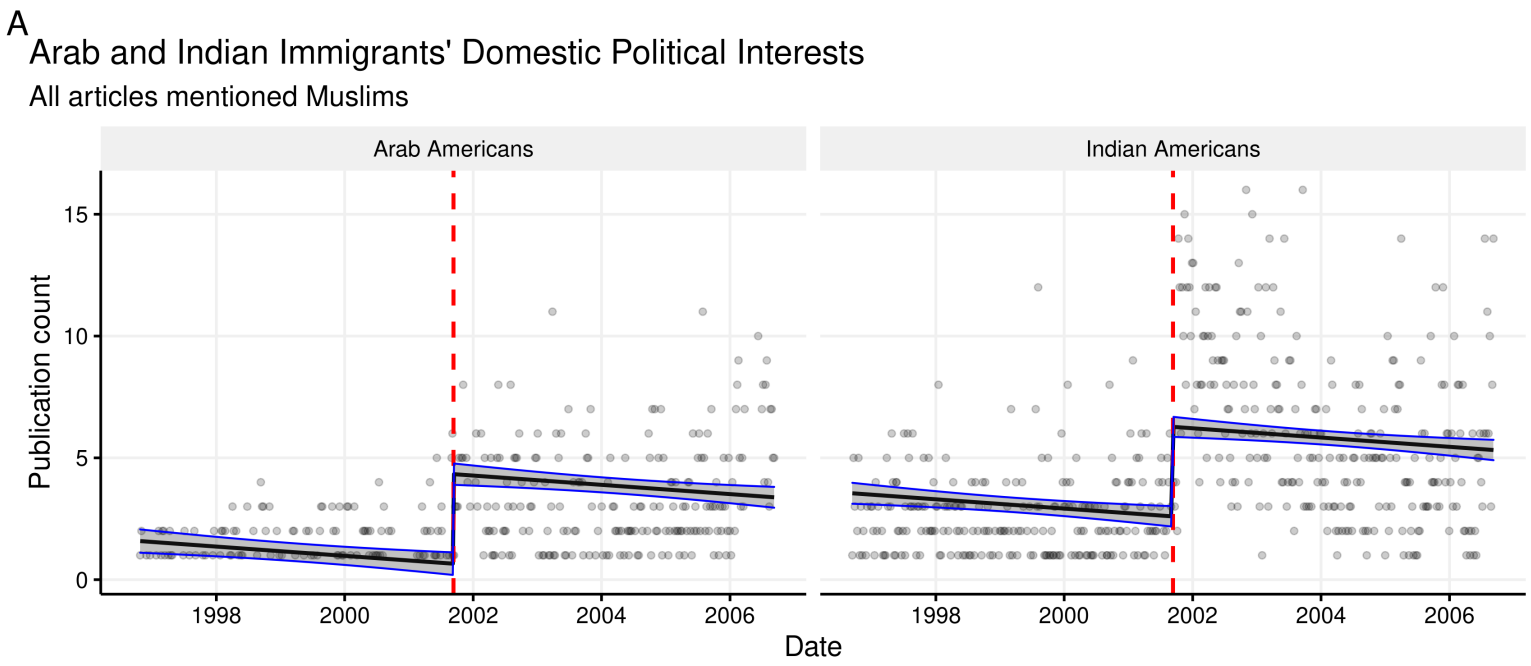

B

Arab and Indian Immigrants' International Political Interests

All articles mentioned Muslims
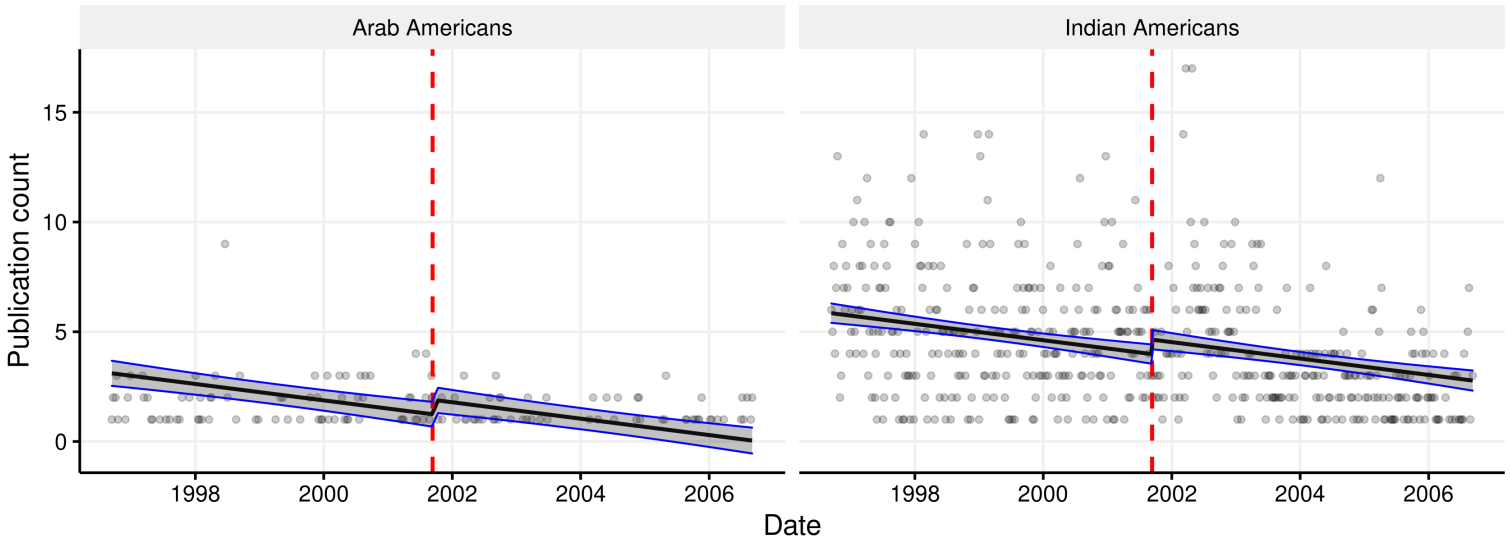

Source: Ethnic Newswatch

Figure 1: ITS design analysis results 


\section{Dependent variable:}

The publication count for Muslim-related articles on Domestic politics International politics

\begin{tabular}{|c|c|c|}
\hline Intervention & $3.676^{* * *}(0.349)$ & $0.661^{*}(0.382)$ \\
\hline Date & $-0.001^{* * *}(0.0002)$ & $-0.001^{* * *}(0.0002)$ \\
\hline Indian Americans & $1.941^{* * *}(0.182)$ & $2.740^{* * *}(0.241)$ \\
\hline Constant & $6.686^{* * *}(1.799)$ & $13.086^{* * *}(1.970)$ \\
\hline Observations & 803 & 630 \\
\hline $\mathrm{R}^{2}$ & 0.289 & 0.236 \\
\hline Adjusted $\mathrm{R}^{2}$ & 0.287 & 0.232 \\
\hline Residual Std. Error & $2.497(\mathrm{df}=799)$ & $2.458(\mathrm{df}=626)$ \\
\hline F Statistic & $108.517^{* * *}(\mathrm{df}=3 ; 799)$ & $64.348^{* * *}(\mathrm{df}=3 ; 626)$ \\
\hline
\end{tabular}

Table 1: ITS design analysis results (OLS) 
The effect of the September 11 attacks on the shift in the locus of targeted immigrant communities' political attention is more striking when we compare the patterns appearing in the mainstream and ethnic newspaper articles. In Figure 2, the Y-axis and X-axis are identical as in Figure 1. The difference is, in this figure, the panel A and C are based on the New York Times articles. The panel $\mathrm{B}$ and $\mathrm{D}$ are based on the pooled ethnic newspaper articles. We put the newspaper sources together to make an easy comparison between the mainstream and ethnic newspaper articles. Again, the line plots indicate the regression models' fitted values, and the grey areas represent their $95 \%$ confidence intervals. The panel $\mathrm{A}$ and $\mathrm{C}$ show that the effect size is far smaller among the host population than among the targeted immigrant groups. If we compare the coefficients of the intervention variable, it is $46 \%$ smaller among the host population (for more information, see Table E.1 in Appendix E).

The other interesting finding is whereas the host population shows increasing interest in the treatment of Muslims overseas over time, the targeted immigrant groups' exhibit an opposite pattern (see panel B and D in Figure 2). This pattern confirms that the shift from international to domestic politics is a unique phenomenon among the targeted immigrant groups.

\section{Discussion and Conclusion}

We did several robustness checks to add more credibility to the findings. One particular problem is autocorrelation, or the linear correlation between a time series and a lagged version of itself. When this occurs, confidence intervals could be much narrow than true values. We checked whether autocorrelation existed using the acf() function in $\mathrm{R}$ and identified a weak seasonal trend, especially for U.S. domestic politics news (see Figure F.1 in Appendix F).

To address this problem, we used generalized least squares (GLS) for an alternative modeling approach. Unlike OLS, GLS assumes a certain degree of correlation between the residuals and a regression model. ${ }^{12}$

\footnotetext{
${ }^{12}$ Specifically, two key parameters define the correlation structure: the autoregressive (AR) and the moving average (MA) order. AR specifies how earlier lags predict later ones. MA determines the ways we average and reduce the degree of random noise. We found the combination of AR and MA parameters that creates the best fitting model by testing different GLS models and extracting the Akaike information criterion (AIC) from them. Essentially, the AIC
} 
A

NYT Articles on Domestic Politics

All articles mentioned Muslims

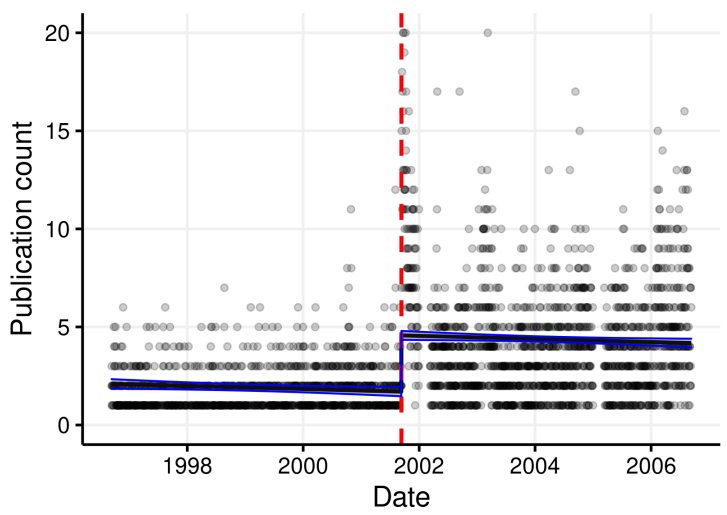

C

NYT Articles on International Politics

All articles mentioned Muslims

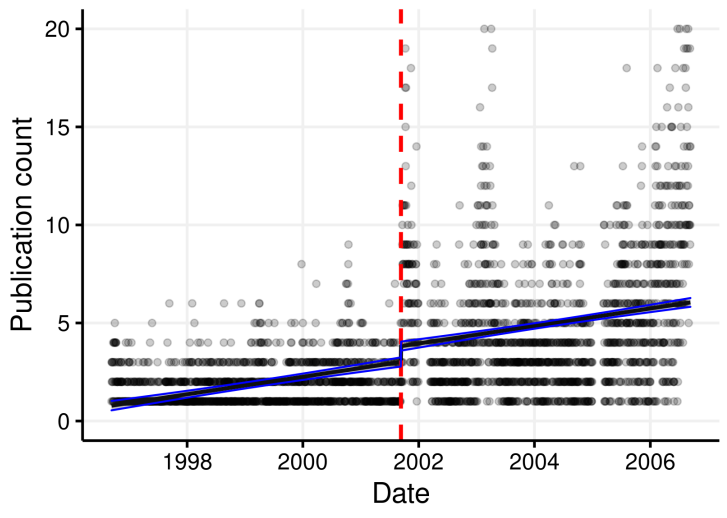

Source: New York Times
B

\section{Ethnic Newspaper Articles on Domestic Politics \\ All articles mentioned Muslims}

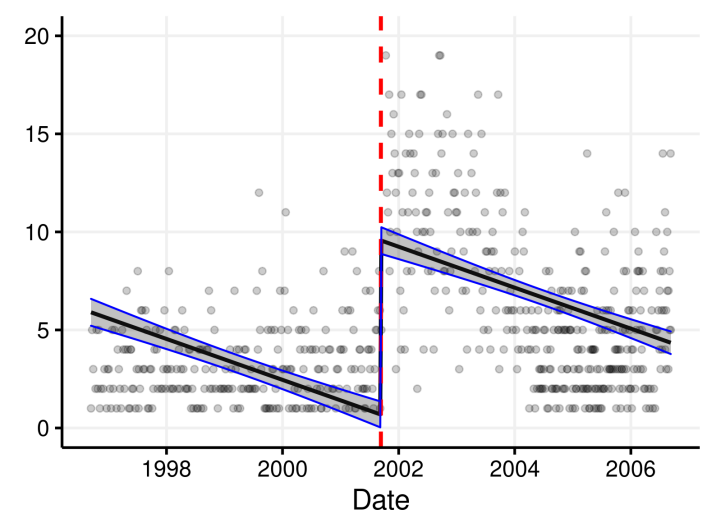

D

Ethnic Newspaper Articles on International Politics

All articles mentioned Muslims

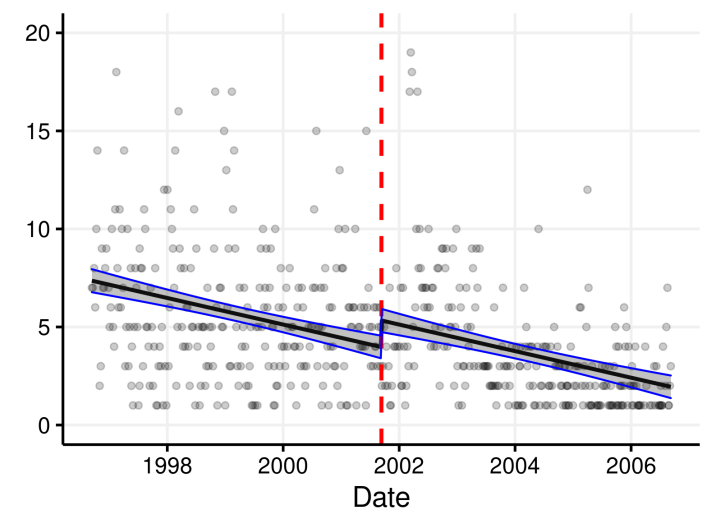

Source: Ethnic NewsWatch

Figure 2: NYT Articles (left) and Ethnic Newspaper Articles (right)

Compared to the OLS results, the GLS results showed much larger standard errors. This change affected the statistical significance of key regression coefficients. Table 2 shows that the treatment effect for the increase in the number of published articles on international politics was no longer statistically significant even when we lowered the significance level to $p<0.1$. Also, the new modeling approach made effect sizes slightly smaller.

penalizes overfitting models, and thus a lower AIC score indicates a better model fit. 


\begin{tabular}{lcc}
\hline \hline & \multicolumn{2}{c}{ Dependent variable: } \\
\cline { 2 - 3 } & \multicolumn{2}{c}{ The publication count for Muslim-related articles on } \\
& Domestic politics & International politics \\
\hline Intervention & $2.375^{* * *}(0.775)$ & $0.219(0.612)$ \\
Date & $0.0002(0.0004)$ & $-0.001^{* *}(0.0003)$ \\
Indian Americans & $1.762^{* * *}(0.635)$ & $2.708^{* * *}(0.353)$ \\
Constant & $-0.430(4.494)$ & $9.974^{* * *}(3.132)$ \\
\hline Observations & 803 & 630 \\
Log Likelihood & $-1,817.311$ & $-1,449.269$ \\
Akaike Inf. Crit. & $3,648.622$ & $2,916.538$ \\
Bayesian Inf. Crit. & $3,681.406$ & $2,956.492$ \\
\hline \hline Note: & & ${ }^{*} \mathrm{p}<0.1 ;{ }^{* *} \mathrm{p}<0.05 ;{ }^{* * *} \mathrm{p}<0.01$ \\
\hline
\end{tabular}

Table 2: ITS design analysis results (GLS)

\begin{tabular}{lcc}
\hline \hline & \multicolumn{2}{c}{ Dependent variable: } \\
\cline { 2 - 3 } & \multicolumn{2}{c}{ The publication count for Muslim-related articles on } \\
& Domestic politics & International politics \\
\hline Intervention & $2.264^{* * *}(0.349)$ & $0.454^{* *}(0.190)$ \\
Date & $-0.001^{* *}(0.0002)$ & $-0.0004^{* * *}(0.0001)$ \\
India Abroad & $0.421(0.501)$ & $1.148^{* * *}(0.133)$ \\
News India - Times & $0.335(0.502)$ & $0.844^{* * *}(0.140)$ \\
Constant & $6.628^{* * *}(2.247)$ & $6.052^{* * *}(1.005)$ \\
\hline Observations & 956 & 931 \\
Log Likelihood & $-1,710.137$ & $-1,705.024$ \\
Akaike Inf. Crit. & $3,436.274$ & $3,428.049$ \\
Bayesian Inf. Crit. & $3,475.134$ & $3,471.527$ \\
\hline \hline Note: & \multicolumn{2}{c}{${ }^{*} \mathrm{p}<0.1 ;{ }^{* *} \mathrm{p}<0.05 ;{ }^{* * *} \mathrm{p}<0.01$}
\end{tabular}

Table 3: ITS design analysis results with source fixed effects 
Another possible limitation of the pooled analysis used in Table 1 is the loss of observations. Because the model used the dates on which both the Arab and Indian American newspaper articles were published, the observations included when either one of the two newspapers published articles on Muslim communities may have been missing from the data. Figure G.1 in Appendix shows G that the Indian American newspapers had a larger number of observations and drew more evenly on multiple sources. In contrast, the Arab American newspapers relied heavily on the Arab American News. To address this problem, we filtered the data, only included Indian American newspapers, and replaced the group variable in the GLS model used in Table 3 with the source variable that indicated the publication source of a newspaper article. This specification change increased the size of the observations by $30 \%$ (from $1,499^{13}$ to 1,954 ) and the difference between the treatment effect for the number of published articles on domestic politics and international politics by $33 \%$ (from 1.425 to 1.901). Due to the increase in the sample size, the standard errors became narrower, and the treatment effect of the increase in the number of published articles on international politics again became statistically significant.

The other limitation is the choice of the timeframe. The 5-year window before and after the data collection intervention, from September 1996 to September 2006, could be arbitrary. For instance, we might observe a larger effect of the intervention if we reduced the time frame immediately after the intervention. Figure D.1 in Appendix D confirms that this is indeed the case. Whether one uses the GLS or OLS models, the effect size was larger in the one year after the intervention (four articles a day) then decreased to the three articles a day afterward. However, whether one extends the period to the year 2004 or 2006 did not cause a significant decline in the effect size. Therefore, extending the time frame to the year 2006 might underestimate the intervention's immediate effect; however, it also helps us see that the effect is durable.

There are a series of significant implications to our findings. This study demonstrates how threat can shift the locus of targeted immigrant groups' political attention. We find that for both Arab and Indian Americans, the threat induced from the 9/11 attacks and their aftermath caused

\footnotetext{
${ }^{13}$ Because the dependent variable was not an individual but the count of the articles published per day, the number of total observations was smaller than the size of the raw dataset $(n=5,684)$.
} 
a greater interest in domestic politics, resulting in more coverage within respective newspapers. This significant increase in attention to the politics of the host society could lead to further political incorporation, engagement, and mobilization among targeted immigrant populations.

The threat caused by the 9/11 attacks could have motivated changes to how immigrant communities interact with their host country. Recent work has demonstrated that more integration among immigrants leads to higher levels of perceived marginalization (Lajevardi et al., 2020). Here, our results call to a reversal of that causal arrow. Arab and Indian American communities experienced more discrimination in light of the terrorist attacks, leading to more concern for American domestic politics. In short, discrimination led to more integration of immigrant communities.

Our study also shows how automated text classification can be used to identify the long-term effects of threats on marginalized populations. Leveraging a terrorist attack as an instrument for causal identification is not a novel empirical strategy. While several studies have examined the political, economic, social, and psychological impacts of terrorist attacks (Metcalfe, Powdthavee and Dolan, 2011, Montalvo, 2011, 2012, Averett and Wang, 2012, Hersh, 2013, Averett and Wang, 2016, Coupe, 2017, Balcells and Torrats-Espinosa, 2018, Jungkunz, Helbling and Schwemmer, 2019, Álvarez-Benjumea and Winter, 2020), the focus of these studies has been exclusively on majority populations. This focus could be theoretically driven or methodological - namely, because most standard panel data do not include sufficient observations of minority populations to avoid a lack of statistical power. Our project shows that automatically classifying ethnic newspaper articles could provide a viable solution to overcome this inherent data limitation and subject restriction in the literature.

The project also provides two accompanying $\mathrm{R}$ packages. These $\mathrm{R}$ packages help researchers with little technical expertise to automatically collect large-scale longitudinal data from the mainstream and ethnic newspaper published in the U.S. In essence, the tools make such digital data collection more accessible and offer new opportunities for comparative media studies. 


\section{References}

Acharya, Avidit, Matthew Blackwell and Maya Sen. 2018. Deep Roots: How Slavery Still Shapes Southern Politics. Princeton University Press.

Ahluwalia, Muninder K and Laura Pellettiere. 2010. "Sikh Men Post-9/11: Misidentification, Discrimination, and Coping." Asian American Journal of Psychology 1(4):303.

Alsultany, Evelyn. 2012. Arabs and Muslims in the Media: Race and Representation After 9/11. Nyu Press.

Álvarez-Benjumea, Amalia and Fabian Winter. 2020. "The Breakdown of Antiracist Norms: A Natural Experiment on Hate Speech After Terrorist Attacks." Proceedings of the National Academy of Sciences .

Averett, Susan L and Yang Wang. 2012. "Identification of the Effect of Depression on Risky Sexual Behavior: Exploiting A Natural Experiment." American Economic Review 102(3):570-74.

Averett, Susan L and Yang Wang. 2016. "Identifying the Causal Effect of Alcohol Abuse on the Perpetration of intimate Partner Violence By Men Using A Aatural Experiment." Southern Economic Journal 82(3):697-724.

Azab, Marian and Wayne A Santoro. 2017. "Rethinking Fear and Protest: Racialized Repression of Arab Americans and the Mobilization Benefits of Being Afraid." Mobilization: An international Quarterly 22(4):473-491.

Balcells, Laia and Gerard Torrats-Espinosa. 2018. "Using A Natural Experiment to Estimate the Electoral Consequences of Terrorist Attacks." Proceedings of the National Academy of Sciences 115(42):10624-10629.

Blalock, Hubert M. 1967. Toward A theory of Minority-Group Relations. Wiley.

Bleakley, Hoyt and Aimee Chin. 2008. "What Holds Back the Second Generation? the intergenerational Transmission of Language Human Capital Among Immigrants.” Journal 
of Human Resources 43(2):267-298.

Bloemraad, Irene, Fabiana Silva and Kim Voss. 2016. "Rights, Economics, or Family? Frame Resonance, Political Ideology, and the Immigrant Rights Movement." Social Forces 94(4):1647-1674.

Blumer, Herbert. 1958. "Race Prejudice As A Sense of Group Position.” Pacific Sociological Review 1(1):3-7.

Breiman, Leo. 2001. "Random Forests.” Machine Learning 45(1):5-32.

Cainkar, Louise and Sunaina Maira. 2005. "Targeting Arab/Muslim/South Asian Americans: Criminalization and Cultural Citizenship.” Amerasia Journal 31(3):1-28.

Campbell, Donald T and H Laurence Ross. 1968. "The Connecticut Crackdown on Speeding: Time-Series Data in Quasi-Experimental Analysis.” Law and Society Review pp. 33-53.

Carlos, Roberto F. 2021. "The Politics of the Mundane.” American Political Science Review p. $1-15$.

Carpini, Michael X Delli and Scott Keeter. 1996. What Americans Know about Politics and Why It Matters. Yale University Press.

Chandrasekhar, Charu A. 2003. "Flying While Brown: Federal Civil Rights Remedies to Post-9/11 Airline Racial Profiling of South Asians.” Asian Lj 10:215.

Cho, Wendy K Tam. 1999. "Naturalization, socialization, participation: Immigrants and (non-) voting." The Journal of Politics 61(4):1140-1155.

Cho, Wendy K Tam, James G Gimpel and Tony Wu. 2006. "Clarifying the Role of Ses in Political Participation: Policy Threat and Arab American Mobilization.” The Journal of Politics 68(4):977-991.

Cohen, Cathy J and Matthew D Luttig. 2019. "Reconceptualizing Political Knowledge: Race, Ethnicity, and Carceral Violence.” Perspectives on Politics pp. 1-14. 
Cohen, Elisia L. 2002. “Online Journalism As Market-Driven Journalism.” Journal of Broadcasting\& Electronic Media 46(4):532-548.

Converse, Philip E. 1975. Public Opinion and Voting Behavior. In Handbook of Political Science, ed. Fred I. Greenstein and Nelson W. Polsby. Vol. 4 pp. 75-169.

Cook, Thomas D. and Donald Thomas Campbell. 1979. Quasi-Experimentation: Design and Analysis Issues for Field Settings. Houghton Mifflin.

Coupe, Tom. 2017. "The Impact of Terrorism on Expectations, Trust and Happiness-The Case of the November 13 Attacks in Paris, France." Applied Economics Letters 24(15):10841087.

Craig, Maureen A, Julian M Rucker and Jennifer A Richeson. 2018. "The Pitfalls and Promise of increasing Racial Diversity: Threat, Contact, and Race Relations in the 21st Century." Current Directions in Psychological Science 27(3):188-193.

Donald, Horowitz. 1985. Ethnic Groups in Conflict. University of California Press.

Eicker, Friedhelm. 1967. Limit theorems for Regressions With Unequal and Dependent Errors. In Proceedings of the Fifth Berkeley Symposium on Mathematical Statistics and Probability. Vol. 1 Berkeley, CA: University of California Press pp. 59-82.

Enos, Ryan D. 2016. "What the Demolition of Public Housing Teaches Us about the Impact of Racial Threat on Political Behavior.” American Journal of Political Science 60(1):123-142.

Espiritu, Le Yen. 1992. Asian American Panethnicity: Bridging institutions and Identities. Temple University Press.

Ewing, Katherine Pratt. 2008. Being and Belonging: Muslims in the United States Since 9/11. Russell Sage Foundation.

Finn, Rachel L. 2011. "Surveillant Staring: Race and the Everyday Surveillance of South Asian Women After 9/11.” Surveillance \& Society 8(4):413-426. 
Foner, Nancy and Joanna Dreby. 2011. "Relations Between the Generations in Immigrant Families." Annual Review of Sociology 37:545-564.

Freund, Yoav and Robert Schapire. 1999. "A Short introduction to Boosting.” Journal of Japanese Society for Artificial intelligence 14(771-780):1612.

Friedman, Jerome, Trevor Hastie, Robert Tibshirani et al. 2000. "Additive Logistic Regression: A Statistical View of Boosting." The Annals of Statistics 28(2):337-407.

Fugita, Stephen S and David J OBrien. 2011. Japanese American Ethnicity: The Persistence of Community. University of Washington Press.

Gutierrez, Angela, Angela X Ocampo, Matt A Barreto and Gary Segura. 2019. "Somos Mas: How Racial Threat and Anger Mobilized Latino Voters in the Trump Era.” Political Research Quarterly 72(4):960-975.

Hersh, Eitan D. 2013. "Long-Term Effect of September 11 on the Political Behavior of Victims' Families and Neighbors." Proceedings of the National Academy of Sciences 110(52):20959-20963.

Hosokawa, Bill. 1982. JACL: In Quest of Justice. W. Morrow.

Huber, Peter J et al. 1967. The Behavior of Maximum Likelihood Estimates Under Nonstandard Conditions. In Proceedings of the Fifth Berkeley Symposium on Mathematical Statistics and Probability. Vol. 1 University of California Press pp. 221-233.

Ishizuka, Karen. 2016. Serve the People: Making Asian America in the Long Sixties. Verso Books.

Jungkunz, Sebastian, Marc Helbling and Carsten Schwemmer. 2019. "Xenophobia Before and After the Paris 2015 Attacks: Evidence From A Natural Experiment.” Ethnicities 19(2):271-291.

Key Jr, Valdimer Orlando. 1949. Southern Politics. Vintage Books. 
Kim, Jae Yeon. 2020. "How Other Minorities Gained Access: The War on Poverty and Asian American and Latino Community organizing.” Political Research Quarterly pp. 1-14.

Kuhn, Max and Hadley Wickham. 2020. tidymodels: A Collection of Packages for Modeling and Machine Learning Using Tidyverse Principles.

URL: https://www.tidymodels.org

Lai, Him Mark. 2004. Becoming Chinese American: A History of Communities and institutions. Rowman Altamira.

Lajevardi, Nazita. 2020. Outsiders At Home: The Politics of American Islamophobia. Cambridge University Press.

Lajevardi, Nazita, Kassra AR Oskooii, Hannah L Walker and Aubrey L Westfall. 2020. “The Paradox Between integration and Perceived Discrimination Among American Muslims." Political Psychology 41(3):587-606.

Liska, Allen E. 1992. Social Threat and Social Control. State University of New York Press.

McManus, John H. 1994. Market-Driven Journalism: Let the Citizen Beware? Sage Publications.

Merskin, Debra. 2004. "The Construction of Arabs As Enemies: Post-September 11 Discourse of George W. Bush.” Mass Communication\& Society 7(2):157-175.

Metcalfe, Robert, Nattavudh Powdthavee and Paul Dolan. 2011. "Destruction and Distress: Using A Quasi-Experiment to Show the Effects of the September 11 Attacks on Mental Well-Being in the United Kingdom.” The Economic Journal 121(550):F81-F103.

Montalvo, Jose G. 2011. "Voting After the Bombings: A Natural Experiment on the Effect of Terrorist Attacks on Democratic Elections.” Review of Economics and Statistics 93(4):11461154.

Montalvo, Jose G. 2012. "Re-Examining the Evidence on the Electoral Impact of Terrorist Attacks: The Spanish Election of 2004.” Electoral Studies 31(1):96-106. 
Mutz, Diana C. 2018. "Status Threat, Not Economic Hardship, Explains the 2016 Presidential Vote." Proceedings of the National Academy of Sciences 115(19):E4330-E4339.

Ngai, Mae M. 2014. Impossible Subjects: Illegal Aliens and the Making of Modern AmericaUpdated Edition. Princeton University Press.

Norris, Pippa, Montague Kern and Marion Just. 2004. Framing Terrorism: The News Media, the Government and the Public. Routledge.

Outten, H Robert, Michael T Schmitt, Daniel A Miller and Amber L Garcia. 2012. "Feeling Threatened about the Future: Whites' Emotional Reactions to Anticipated Ethnic Demographic Changes.” Personality and Social Psychology Bulletin 38(1):14-25.

Panagopoulos, Costas. 2006. "The Polls-Trends: Arab and Muslim Americans and Islam in the Aftermath of 9/11." International Journal of Public Opinion Quarterly 70(4):608-624.

Pantoja, Adrian D and Gary M Segura. 2003. "Fear and Loathing in California: Contextual Threat and Political Sophistication Among Latino Voters.” Political Behavior 25(3):265286.

Perea, Juan F. 1997. Immigrants Out!: The New Nativism and the Anti-Immigrant Impulse in the United States. Vol. 76 Nyu Press.

Pérez, Efrén O. 2015. "Xenophobic Rhetoric and Its Political Effects on Immigrants and their Co-Ethnics." American Journal of Political Science 59(3):549-564.

Quillian, Lincoln. 1996. “Group Threat and Regional Change in Attitudes Toward AfricanAmericans.” American Journal of Sociology 102(3):816-860.

Reny, Tyler, Bryan Wilcox-Archuleta and Vanessa Cruz Nichols. 2018. Threat, Mobilization, and Latino Voting in the 2018 Election. In The Forum. Vol. 16 De Gruyter pp. 573-599.

Rudrappa, Sharmila. 2004. Ethnic Routes to Becoming American: Indian Immigrants and the Cultures of Citizenship. Rutgers University Press. 
Selod, Saher. 2015. "Citizenship Denied: The Racialization of Muslim American Men and Women Post-9/11." Critical Sociology 41(1):77-95.

Stepick, Alex and Carol Dutton Stepick. 2002. "Becoming American, Constructing Ethnicity: Immigrant Youth and Civic Engagement." Applied Developmental Science 6(4):246-257.

Tibshirani, Robert. 1996. "Regression Shrinkage and Selection Via the Lasso." Journal of the Royal Statistical Society 58(1):267-288.

Towler, Christopher C and Christopher S Parker. 2018. "Between Anger and Engagement: Donald Trump and Black America." Journal of Race, Ethnicity and Politics 3(1):219-253.

Umbach, Greg and Dan Wishnoff. 2008. "Strategic Self-Orientalism: Urban Planning Policies and the Shaping of New York City's Chinatown, 1950-2005.” Journal of Planning History $7(3): 214-238$.

Umemoto, Karen. 1989. ““'On Strike!” San Francisco State College Strike, 1968-69: The Role of Asian American Students." Amerasia Journal 15(1):3-41.

Valentino, Nicholas A, Stuart N Soroka, Shanto Iyengar, Toril Aalberg, Raymond Duch, Marta Fraile, Kyu S Hahn, Kasper M Hansen, Allison Harell, Marc Helbling et al. 2019. "Economic and Cultural Drivers of Immigrant Support Worldwide." British Journal of Political Science 49(4):1201-1226.

Verba, Sidney, Kay Lehman Schlozman and Henry E Brady. 1995. Voice and Equality: Civic Voluntarism in American Politics. Harvard University Press.

Võ, Linda Trinh. 2004. Mobilizing An Asian American Community. Philadelphia, PA: Temple University Press.

Wang, Xia. 2012. "Undocumented Immigrants As Perceived Criminal Threat: A Test of the Minority Threat Perspective." Criminology 50(3):743-776.

Weaver, Vesla, Gwen Prowse and Spencer Piston. 2019. “Too Much Knowledge, Too Little Power: An Assessment of Political Knowledge in Highly Policed Communities." The 
Journal of Politics 81(3):1153-1166.

Weeks, Brian E. 2015. "Emotions, Partisanship, and Misperceptions: How Anger and Anxiety Moderate the Effect of Partisan Bias on Susceptibility to Political Misinformation.” Journal of Communication 65(4):699-719.

Wei, William. 1993. The Asian American Movement. Philadelphia, PA: Temple University Press.

White, Ariel. 2016. "When Threat Mobilizes: Immigration Enforcement and Latino Voter Turnout." Political Behavior 38(2):355-382.

White, Halbert. 2014. Asymptotic Theory for Econometricians. Academic Press.

Wong, Bernard. 1977. "Elites and Ethnic Boundary Maintenance: A Study of the Roles of Elites in Chinatown, New York City." Urban Anthropology pp. 001-022.

Wong, Janelle S. 2000. "The Effects of Age and Political Exposure on the Development of Party Identification Among Asian American and Latino Immigrants in the United States.” Political Behavior 22(4):341-371.

Yazdiha, Haj. 2014. "Law As Movement Strategy: How the Islamophobia Movement institutionalizes Fear Through Legislation.” Social Movement Studies 13(2):267-274.

Zepeda-Millán, Chris. 2017. Latino Mass Mobilization: Immigration, Racialization, and Activism. Cambridge University Press. 


\section{Online Appendix}

\section{Appendix A Ethnic NewsWatch database}

\begin{tabular}{llr}
\hline Source & Period & $\mathrm{N}$ \\
\hline The Arab American News & $1994-2018$ & 19728 \\
The Arab American View & $2001-2004$ & 129 \\
News India Times & $1993-2018$ & 44244 \\
India Abroad & $1990-2017$ & 49894 \\
India West & $1990-2018$ & 60862 \\
\hline
\end{tabular}

Table A.1: Summary information of the Arab American and Indian American newspapers available at the Ethnic NewsWatch Database, 1996-2006. Retrieved on September 28, 2020. 


\section{Appendix B Model evaluations}

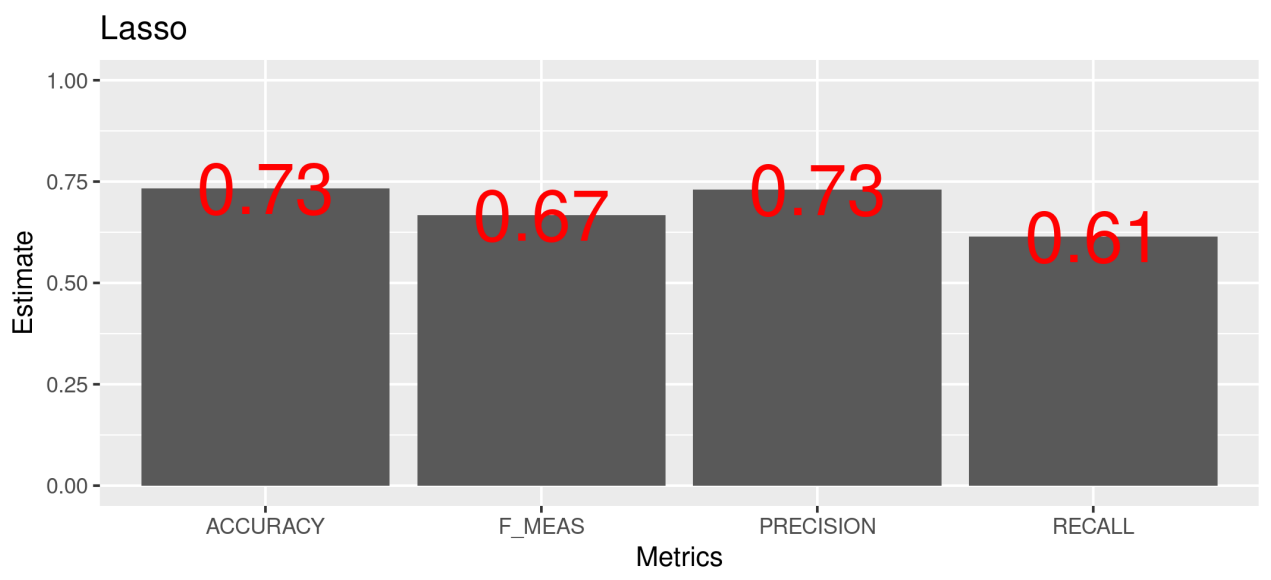

Random forest

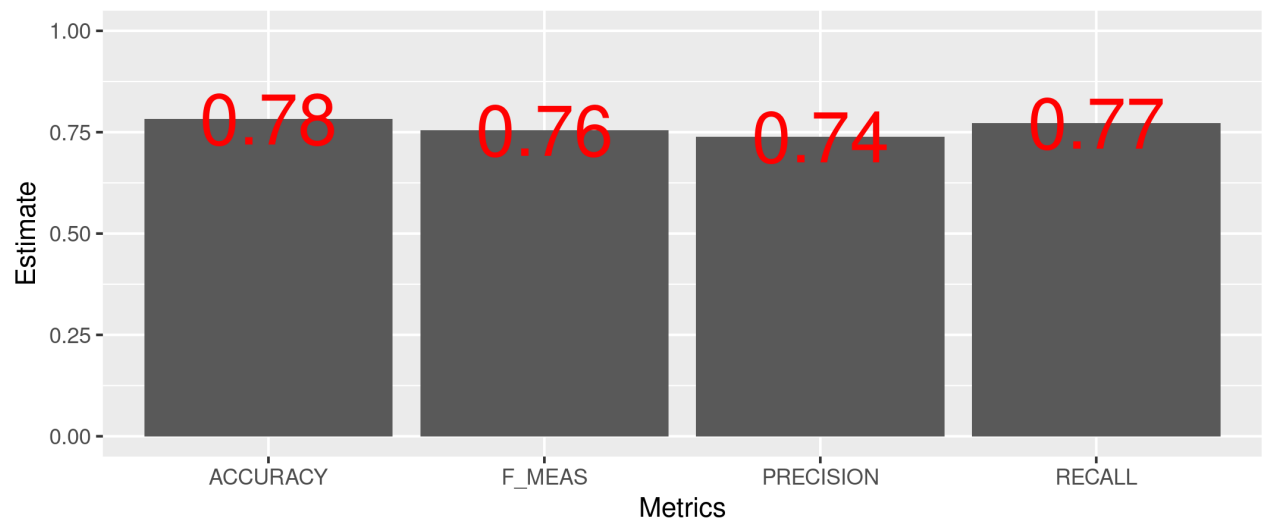

XGBoost

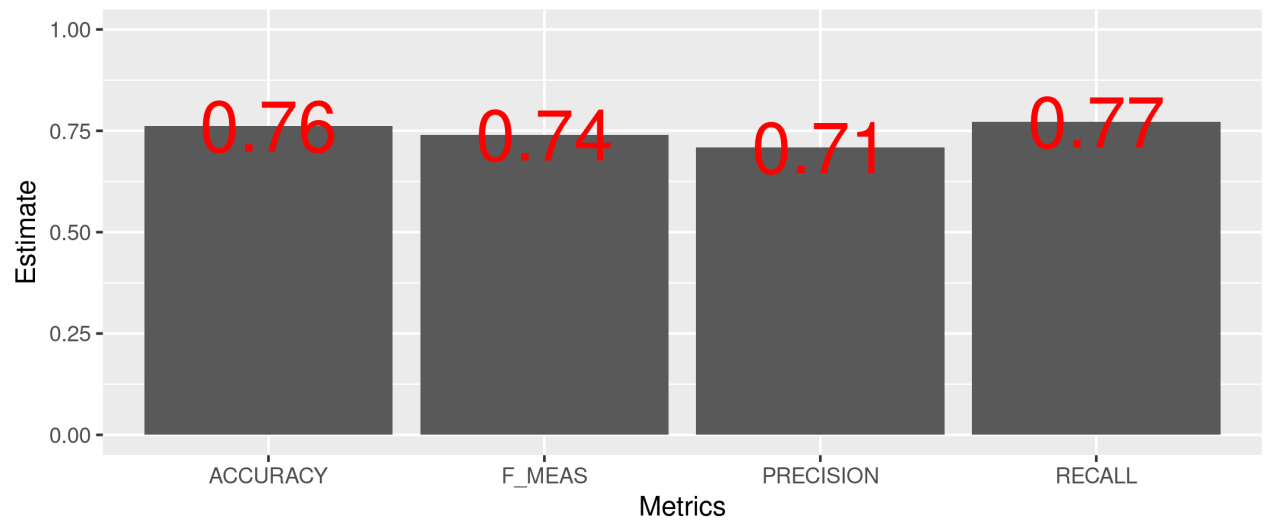

Figure B.1: Machine Learning Outcomes 


\section{Appendix C Robust Standard Errors}

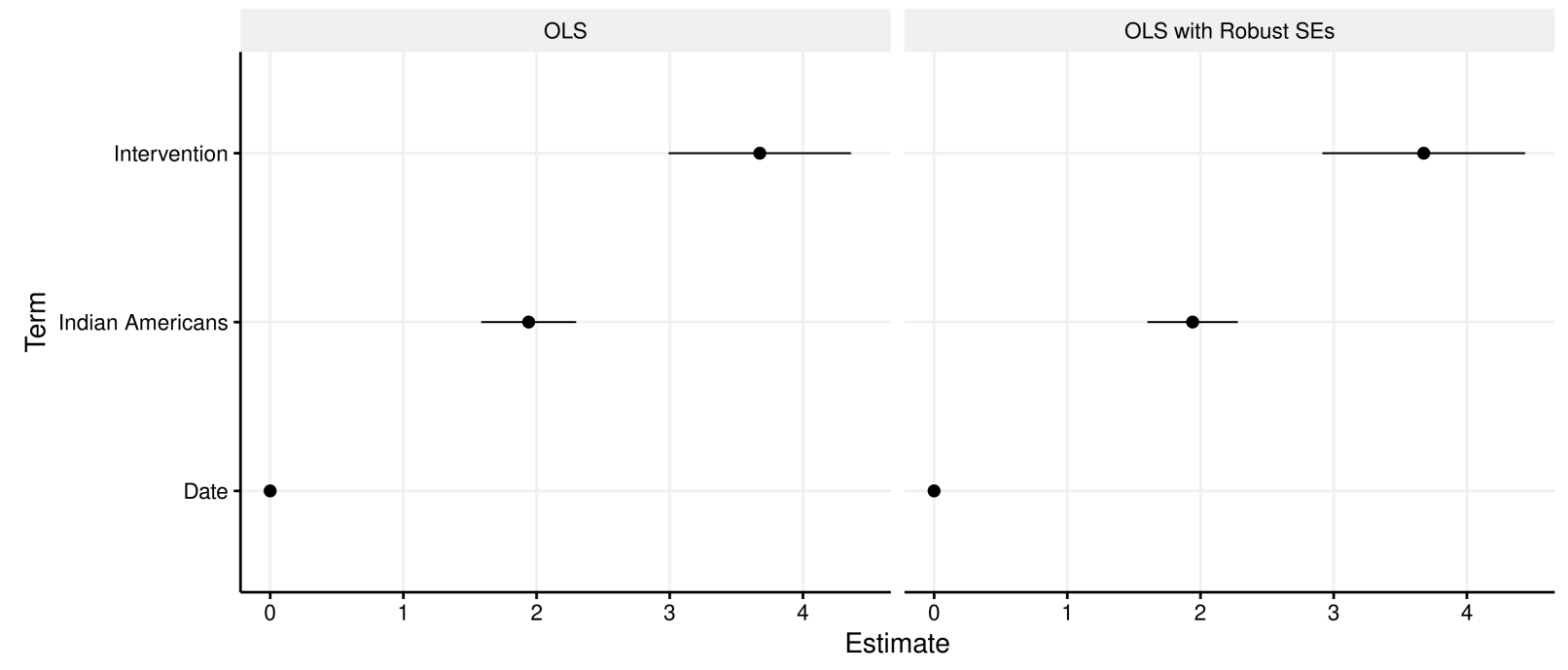

Figure C.1: ITS design analysis results (OLS with robust standard errors) 


\section{Appendix D Duration Effect}

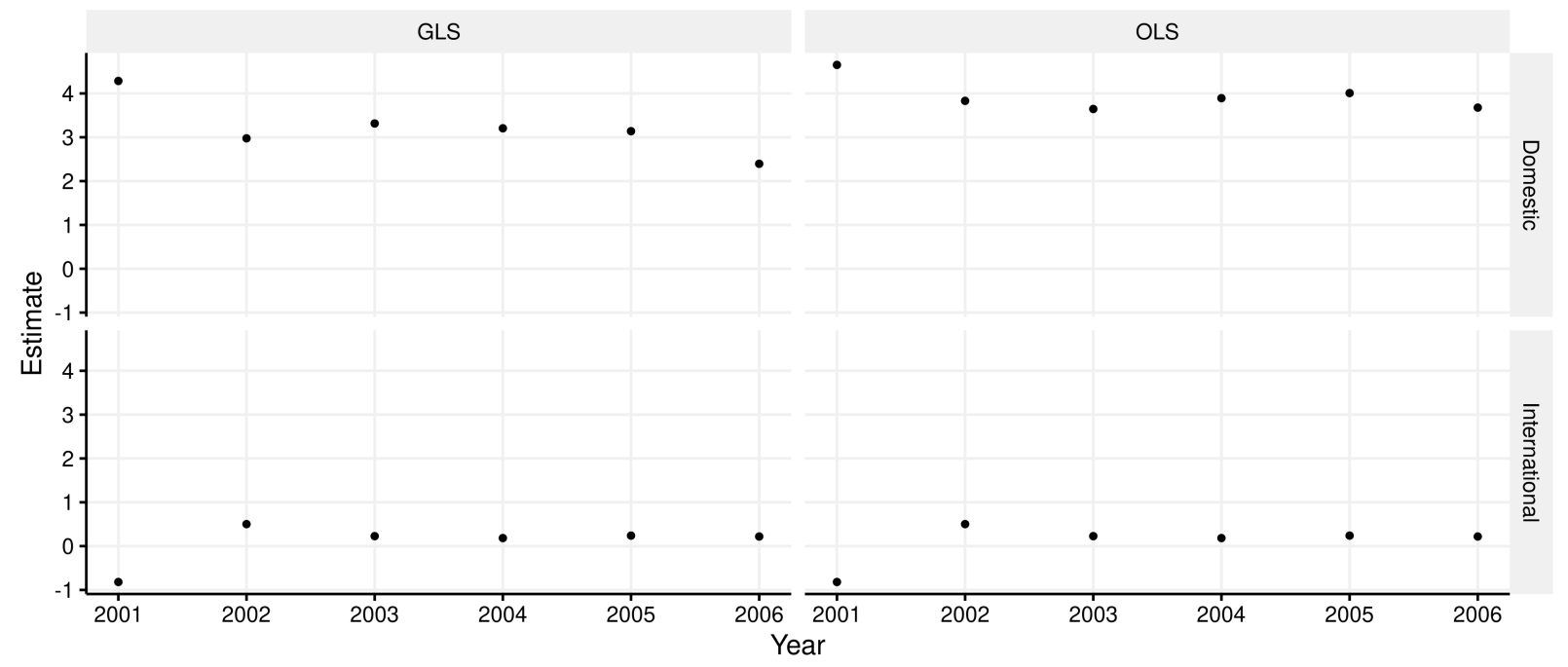

Figure D.1: Duration Effect Analysis 


\section{Appendix E NYT data analysis}

\begin{tabular}{lc}
\hline \hline & Dependent variable: \\
\cline { 2 - 2 } & $\begin{array}{c}\text { The publication count for Muslim-related articles on } \\
\text { Domestic politics }\end{array}$ \\
\hline Intervention & $1.977^{* * *}(0.164)$ \\
Date & $0.0001^{*}(0.0001)$ \\
Constant & $0.337(0.831)$ \\
\hline Observations & 2,684 \\
$\mathrm{R}^{2}$ & 0.211 \\
Adjusted $\mathrm{R}^{2}$ & 0.210 \\
Residual Std. Error & $2.142(\mathrm{df}=2681)$ \\
F Statistic & $358.635^{* * *}(\mathrm{df}=2 ; 2681)$ \\
\hline \hline Note: & ${ }^{*} \mathrm{p}<0.1 ;{ }^{* *} \mathrm{p}<0.05 ;{ }^{* * *} \mathrm{p}<0.01$
\end{tabular}

Table E.1: ITS design analysis results 


\section{Appendix F Autocorrelation test}
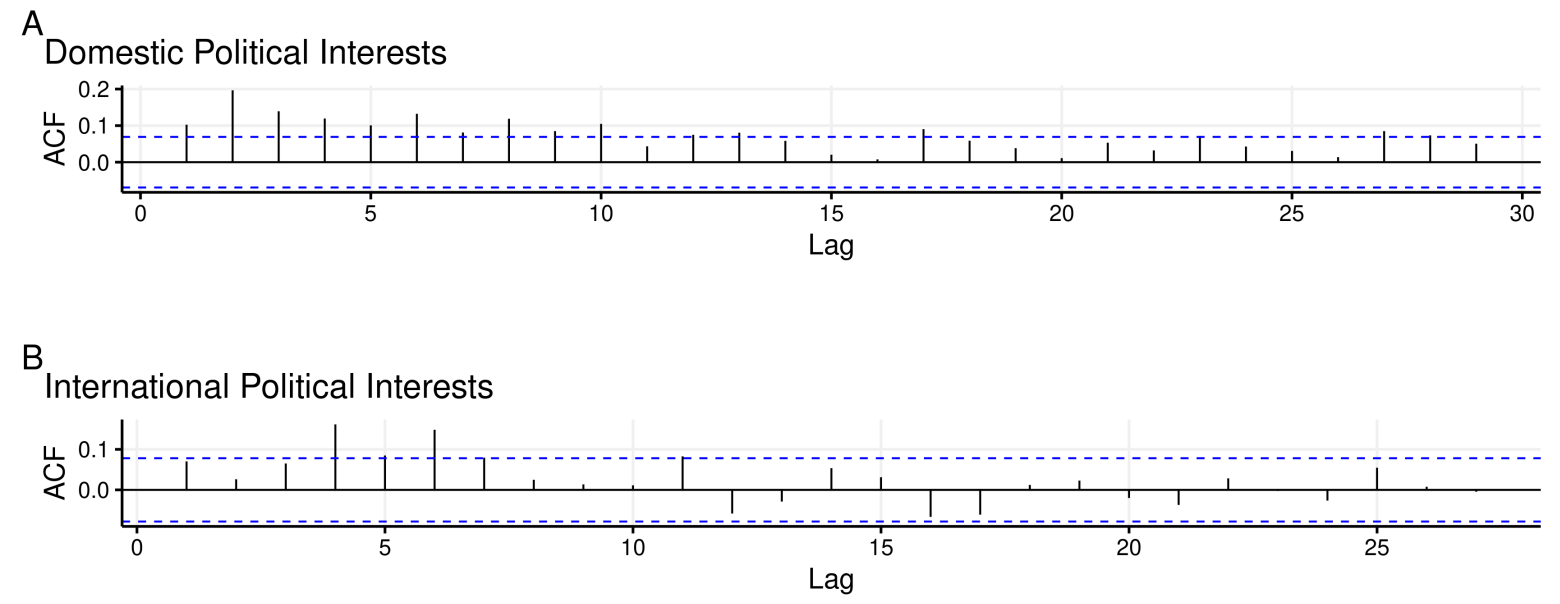

Figure F.1: Autocorrelation plot 


\section{Appendix G Newspaper source analysis}

A Arab and Indian Immigrants' Domestic Political Interests

All articles mentioned Muslims
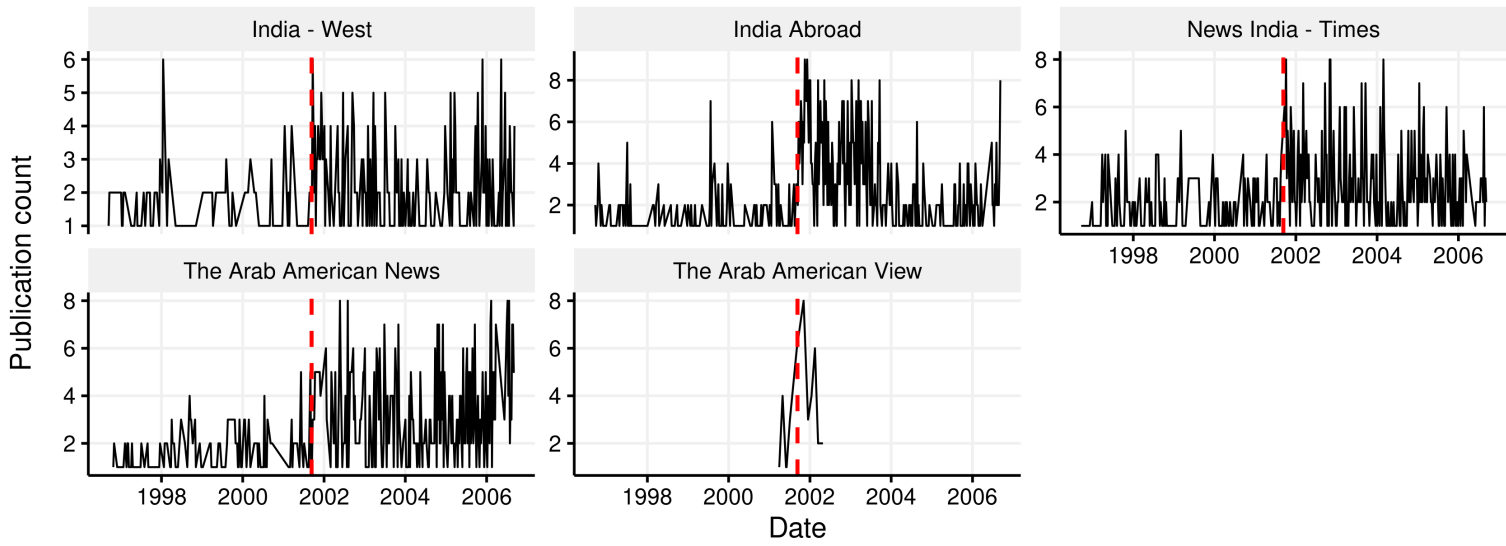

B

Arab and Indian Immigrants' International Political Interests

All articles mentioned Muslims
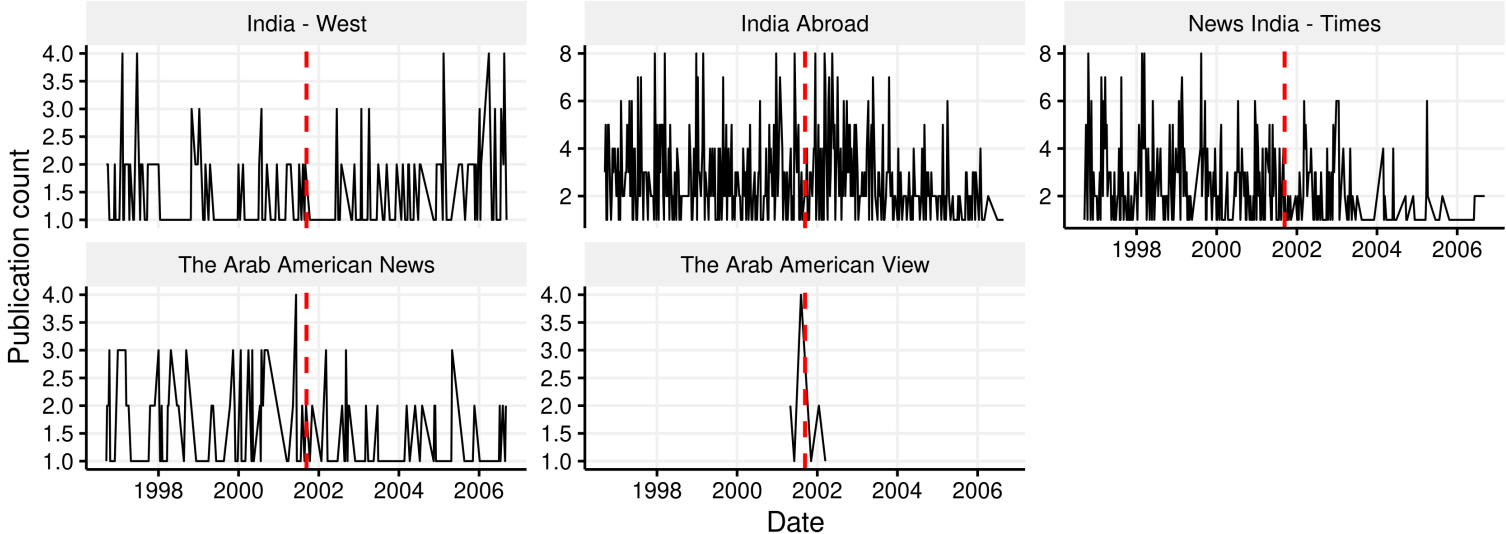

Source: Ethnic Newswatch

Figure G.1: Line plots of raw data faceted by source variable 